\title{
Kemampuan Penghambatan Formulasi Biofungisida Tepung Berbahan Aktif Trichoderma pseudokoningii Rifai Setelah Penyimpanan Terhadap Jamur Ganoderma boninense Pat. secara in vitro
}

\author{
Inhibition Ability of Flour Biofungicide Formulation with Trichoderma pseudokoningii Rifai as \\ Active Ingredients After Storage Against Ganoderma boninense Pat. Fungus in vitro
}

\section{Rachmad Saputra*, Yetti Elfina, Muhammad Ali}

\author{
Jurusan Agroteknologi, Fakultas Pertanian, Universitas Riau, Jl. H.R. Soebrantas, Kampus Binawidya, Pekanbaru \\ 28293 \\ *E-mail Penulis Korespondensi: rachmadsaputra@lecturer.unri.ac.id
}

\begin{abstract}
Trichoderma pseudokoningii fungus has been tested as biological control agents against several pathogenic fungi, including the Ganoderma boninense fungus which causes basal stem rot disease on oil palm. However, in-field testing, the efficacy of antagonistic microbes still showed unstable results. Therefore, it is necessary to package antagonistic microbes in the form of formulations. This study aimed to determine the effect of storage time of flour biofungicide formulations on the viability and antagonism of T. pseudokoningii Rifai in inhibiting the G. boninense pathogenic fungus in vitro. The study was arranged in a Completely Randomized Design with 4 treatments: bagasse (F1), rice husks (F2), dregs (F4) and combinations of bagasse, rice husks and dregs (F12), with three replications. The results showed that the powder biofungicide formulation of $F 2$ (rice husk) was able to maintain the viability of the T. pseudokoningii fungus as indicated by the high number of conidia and high growth rate compared to the other formulations. The T. pseudokoningii fungus in F2 formulation also showed the highest inhibition compared to other formulations after storage for 1 and 2 months.
\end{abstract}

Keywords: biofungicide, formulation, Ganoderma boninense, Trichoderma pseudokoningii

\begin{abstract}
ABSTRAK
Jamur Trichoderma pseudokoningii telah banyak diuji sebagai jamur antagonis pada beberapa jamur patogen termasuk jamur Ganoderma boninense yang menyebabkan penyakit busuk pangkal batang tanaman kelapa sawit. Namun, pada pengujian di lapangan, efikasi mikroba antagonis masih menunjukkan hasil yang tidak stabil. Oleh karenaya perlu pengemasan mikroba antagonis dalam bentuk formulasi. Penelitian ini bertujuan untuk mengetahui pengaruh waktu penyimpanan formulasi biofungisida tepung terhadap viabilitas dan daya antagonis T. Pseudokoningii Rifai dalam menghambat jamur G. boninense Pat. secara in vitro. Penelitian disusun dengan menggunakan rancangan acak lengkap dengan empat perlakuan: ampas tebu (F1), sekam padi (F2), dregs (F4) dan kombinasi ampas tebu, sekam padi dan dregs (F12), dengan tiga ulangan. Hasil penelitian menunjukkan bahwa formulasi biofungisida tepung F2 (sekam padi) mampu menjaga viabilitas jamur T. pseudokoningii yang ditunjukkan dengan banyaknya jumlah konidia dan tingginya kecepatan pertumbuhan dibandingkan dengan formulasi lainnya. Jamur T. pseudokoningii pada formulasi F2 juga menunjukkan daya hambat tertinggi dibandingkan dengan formulasi lainnya setelah penyimpanan 1 dan 2 bulan.
\end{abstract}

Kata kunci: biofungisida, formulasi, Ganoderma boninense, Trichoderma pseudokoningii

\section{PENDAHULUAN}

Penggunaan agens hayati dalam mengendalikan beberapa jenis patogen pada tanaman telah banyak dilakukan dan menunjukkan hasil yang memuaskan. Namun, keberhasilan ini masih banyak dilakukan dalam skala laboratorium. Efikasi mikroba antagonis pada pengujian skala lapangan sering dijumpai hasil yang tidak stabil dalam mengendalikan suatu patogen tananam. Menurut Weller dan Cook (1983), ketidakstabilan tersebut disebabkan oleh tiga faktor, yaitu: 1) daya kompetisi antagonis hilang selama penyimpanan; 2) faktor lingkungan tidak mendukung perkembangan penyakit (tidak ada patogen sasaran) atau adanya interferensi dari patogen bukan sasaran; dan 3) kemampuan kolonisasi rizosfir yang bervariasi. Oleh 
karena itu, mikroba antagonis perlu dikemas menjadi formulasi yang mudah untuk diaplikasikan.

Soepena (1993) menyatakan bahwa untuk pengujian di lapangan, agens hayati harus diformulasikan secara lebih baik. Efektifitas pestisidapestisida termasuk biofungisida seringkali ditentukan oleh formulasi dan cara pemakaian atau aplikasinya (Sastrahidayat, 1986). Menurut Semangun (2006), formulasi fungisida merupakan proses dalam pembuatan fungisida dari bahan aktif yang dicampur dengan bahan lain, sehingga terbentuk formulasi yang siap digunakan. Proses formulasi bertujuan agar bahan teknis dapat diperbaiki sehingga cocok untuk penyimpanan, aplikasi, dan peningkatan efektifitas maupun keamanan bagi manusia dan lingkungan (Untung, 2006).

Jamur Trichoderma sp. yang diformulasikan diharapkan dapat bertahan setelah proses penyimpanan sehingga peranannya sebagai agen pengendali hayati terhadap jamur Ganoderma boninense Pat. yang menyebabkan penyakit busuk pangkal batang pada tanaman kelapa sawit dapat dipertahankan. Namun Suswanto (2014) dalam hasil pengamatan menunjukkan bahwa viabiltas konidia Th-E1002 di dalam keping biofungisida mengalami penurunan selama penyimpanan dalam kantung plastik pada 1 dan 2 bulan berturut-turut 71 dan $26 \%$. Oleh karenanya penelitian ini dilaksanakan bertujuan untuk mengetahui pengaruh waktu penyimpanan formulasi biofungisida tepung terhadap viabilitas dan daya antagonis $T$. pseudokoningii Rifai dalam menghambat jamur Ganoderma boninense Pat. secara in vitro.

\section{METODE PENELITIAN}

Penelitian dilaksanakan di Laboratorium Penyakit Tumbuhan Fakultas Pertanian Universitas Riau. Bahan-bahan yang digunakan adalah formulasi biofungisida tepung berbahan aktif Trichoderma pseudokoningii dan isolat $G$. boninense, medium Potato Dextrosa Agar (PDA) dan medium aktivasi jamur antagonis. Alat-alat yang digunakan dalam penelitian ini adalah mikroskop binokuler, automatic mixer, autoclave, laminar air flow cabinet dan inkubator.

Penelitian ini mengunakan rancangan acak lengkap yang terdiri dari empat perlakuan dan tiga ulangan. Data yang diperoleh dari pengamatan dianalisis secara deskriptif untuk parameter jumlah koloni dan kecepatan pertumbuhan dan secara statistik dengan menggunakan sidik ragam untuk parameter daya hamat. Analisis secara deskriptif ditampilkan dalam bentuk gambar. Data hasil analisis statistik kemudian diuji lanjut dengan Duncan's New Multiple Range Test (DNMRT) pada taraf $5 \%$. Perlakuan yang diuji adalah formulasi biofungisida tepung $(\mathrm{F})$ yang tidak mengalami kerusakan setelah proses penyimpanan berdasarkan penelitian terdahulu (Elfina et al., 2016), yakni: $F_{1}$ (ampas tebu), $\mathrm{F}_{2}$ (sekam padi), $\mathrm{F}_{4}$ (dregs) dan $\mathrm{F}_{12}$ (ampas tebu+sekam padi+dregs).

\section{Jumlah Konidia Jamur Trichoderma pseudokoningii pada Formulasi setelah Penyimpanan}

Jumlah koloni $T$. pseudokoningii hidup pada formulasi biofungisida tepung dihitung dengan Metode Hitungan Cawan sebagai berikut:

$$
J K=j k t \times \frac{1}{f} \times \frac{1}{v}
$$

dengan $\mathrm{JK}=$ jumlah koloni $(\mathrm{CFU} / \mathrm{mL}), \mathrm{jkt}=$ jumlah koloni yang tumbuh pada media, $\mathrm{f}=$ faktor pengenceran dan $\mathrm{v}=$ volume suspensi yang disebar pada media.

\section{Kecepatan Pertumbuhan Koloni Jamur Trichoderma pseudokoningii pada Formula Biofungisida Tepung setelah Penyimpanan ( $\mathrm{mm} / \mathrm{hari})$}

Koloni jamur T. pseudokoningii dari formulasi biofungisida tepung diukur kecepatan pertumbuhannya dengan cara mengukur diameter koloni jamur pada medium PDA yang dilakukan tiap hari hingga cawan petri penuh dan dilakukan pada dua tempat yang tetap pada bagian belakang cawan petri. Data yang digunakan ialah rata-rata dari kecepatan pertumbuhan koloni per hari.

\section{Uji Penghambatan Pertumbuhan Jamur Patogen Ganoderma boninense oleh Trichoderma pseudokoningii pada Formula Biofungisida Tepung setelah Penyimpanan (\%)}

Daya hambat jamur T. pseudokoningii terhadap pertumbuhan jamur $G$. boninense pada formulasi biofungisida tepung dihitung saat hifa jamur $T$. pseudokoningii pada salah satu forrmulasi telah tumbuh dan menyentuh bagian pinggir koloni jamur $G$. boninense pada medium PDA. Kemampuan penghambatan dihitung dengan rumus :

$$
\mathrm{P}=\frac{r_{1}-r_{2}}{r_{1}} \times 100 \%
$$

dengan $\mathrm{P}=$ kemampuan penghambatan $(\%), \mathrm{r} 1=$ jarijari koloni patogen yang menjauhi formula bahan organik, $\mathrm{r} 2$ = jari-jari koloni patogen yang mendekati formula bahan organik.

\section{HASIL DAN PEMBAHASAN}

\section{Viabilitas Jamur Trichoderma pseudokoningii pada Formulasi Biofungisida Tepung setelah Penyimpanan}

Viabilitas jamur T. pseudokoningii pada formulasi biofungisida tepung dapat dilihat dari jumlah konidia dan kecepatan pertumbuhan. Formulasi biofungisida tepung F1 (ampas sagu) dan F2 (sekam padi) menunjukkan komposisi bahan-bahan penyusun yang mampu mempertahankan viabilitas jamur $T$. pseudokoningii setelah penyimpanan. Hal tersebut terlihat dari jumlah konidia pada 1 bulan mengalami 
peningkatan dan menurun pada penyimpanan 2 bulan. Namun penurunan tersebut tidak lebih sedikit dari jumlah konidia pada kondisi awal biofungisida tepung (Gambar 1A). Selain itu, kedua formulasi tersebut juga tidak menurunkan kecepatan pertumbuhan jamur $T$. pseudokoningii (Gambar 1B).

Komposisi bahan organik pada formulasi F1 dan F2 diduga mampu memenuhi kebutuhan nutrisi dasar bagi T. pseudokoningii untuk tumbuh. Menurut Naufala dan Pandebesie (2015) kandungan nutrisi pada sekam padi terdiri dari selulosa $(35,36 \%)$, lignin $(22,31 \%)$ dan hemiselulosa (16,98\%), sedangkan menurut Hidayati et al. (2016), pada ampas tebu terdapat hemiselulosa $25,24 \%$, lignin $(6,4 \%)$, silikat $(9,35 \%)$ dan selulosa $(35,01 \%)$. Kandungan selulosa yang tinggi di formulasi F1 dan F2 ini menjadi sumber nutrisi potensial bagi perkembangan $T$. pseudokoningii. Ratanaphadit et al (2010) menyatakan bahwa Trichoderma sp. memiliki kemampuan untuk menghasilkan enzim selulolitik berupa endoglukanase yang mampu menghidrolisis selulosa.

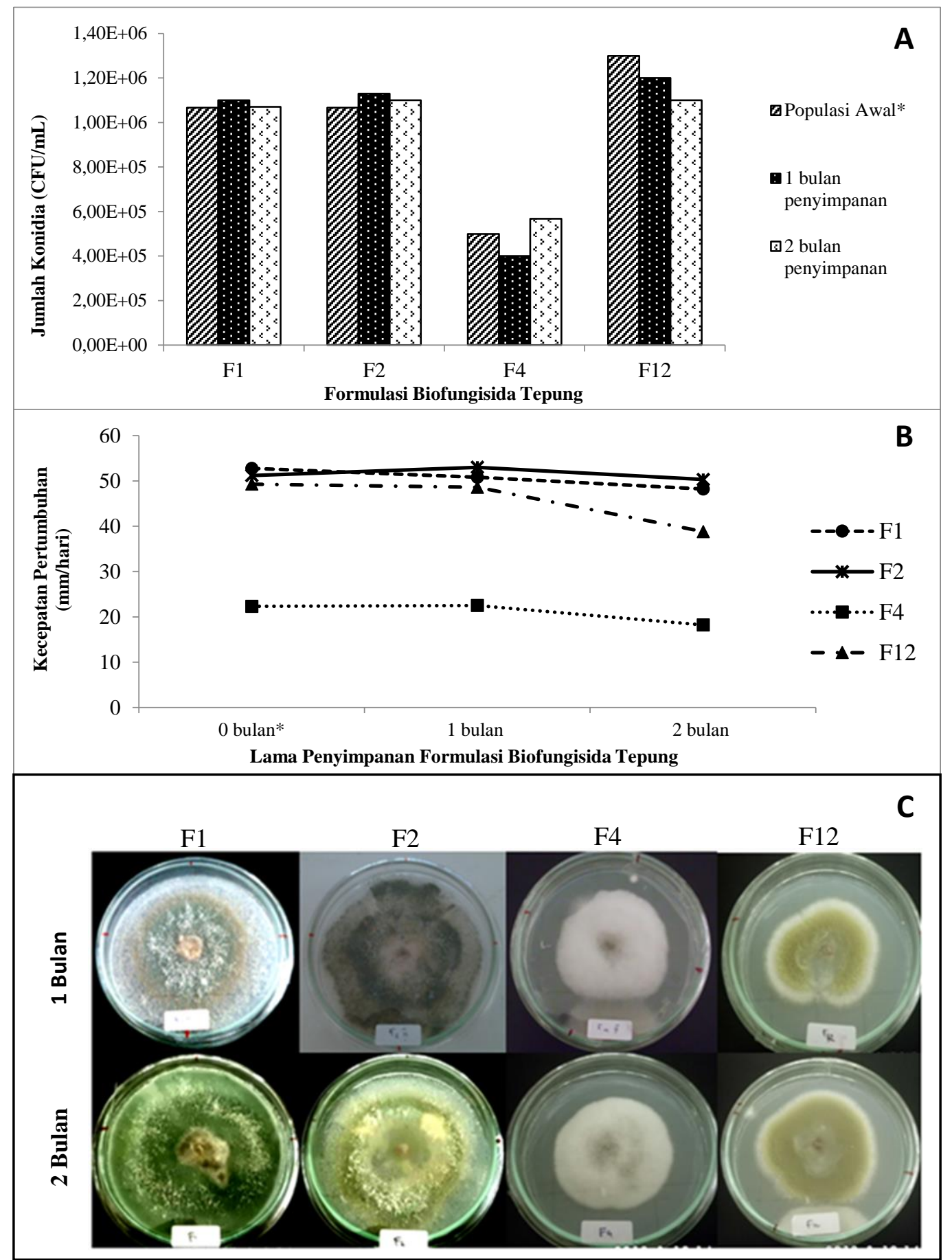

Gambar 1. A) Jumlah konidia; B) trend kecepatan pertumbuhan; dan C) makoskopis jamur Trichoderma pseudokoningii pada formulasi biofungisida tepung setelah penyimpanan (*Elfina et al., 2016) 
Gambar 1 juga menunjukkan formulasi $\mathrm{F} 4$ (dregs) dan F12 (ampas tebu + sekam padi + dregs) menyebabkan penurunan viabilitas jamur $T$. pseudokoningii. Pada formulasi $\mathrm{F} 4$, jamur $T$. pseudokoningii terhambat pertumbuhannya, sedangkan pada formulasi $\mathrm{F} 12$, jumlah konidia $T$. pseudokoningii dan kecepatan pertumbuhannya mengalami penurunan disetiap waktu penyimpanan produk. Menurunnya viabilitas jamur T. pseudokoningii pada formulasi $\mathrm{F} 4$ dan F12 ini disuga karena bahan dregs sebagai penyusun formulasi memiliki senyawa penghambat. Kharisma (2011) di dalam penelitiannya menyebutkan bahwa pemberian dregs $100 \mathrm{~g} / \mathrm{L}$ air menyebabkan diameter koloni jamur T. pseudokoningii lebih kecil yakni $1,82 \mathrm{~cm} /$ hari dibandingkan tanpa pemberian dregs $(2,47 \mathrm{~cm} / \mathrm{hari})$. Oleh karenanya, diameter $T$. pseudokoningi pada formulasi F4 dan F12 lebih kecil dibandingkan formulasi lainnya (Gambar 1C).

Perbedaan komposisi penyusun formulasi biofungisida dan waktu penyimpanan produk hingga dua bulan menunjukkan hasil yang beragam terhadap viabilitas jamur $T$. pseudokoningii pada formulasi biofungisida tepung. Formulasi F1 dan F2 menunjukkan hasil yang baik sedangkan formulasi F4 dan F12 menunjukkan hasil sebaliknya pada viabilitas $T$. pseudokoningii. Menurut Weller dan Cook (1983) formulasi digunakan untuk menstabilkan efektifitas agensia hayati. Viabilitas $T$. harzianum dipengaruhi oleh jenis bahan pembawa yang digunakan pada formulasi pellet dan waktu penyimpanannya (Muljowati dan Purnomowati, 2010).

Kemampuan penghambatan jamur Trichoderma pseudokoningii terhadap jamur patogen Ganoderma boninense pada formulasi biofungisida tepung setelah penyimpanan

Data Tabel 3 menunjukkan formulasi biofungisida tepung $T$. pseudokoningii pada formulasi F2 (sekam padi) dan F1 (ampas tebu) menunjukkan daya hambat tertinggi yang berbeda nyata dengan formulasi F4 (dregs) dan F12 (ampas tebu+sekam padi+dregs) pada penyimpanan formulasi 1 bulan. Namun pada penyimpanan 2 bulan, Formulasi biofungisida tepung F2 menunjukkan hasil berbeda nyata dibandingkan formulasi lainnya.

Formulasi biofungisida tepung F2 (sekam padi) memiliki daya hambat tertinggi setelah disimpan selama 1 bulan $(78,54 \%)$ dan 2 bulan $(78,23 \%)$. Gambar 2 menunjukkan trend daya hambat formulasi ini tidak mengalami penurunan secara signifikan dibandingkan dengan daya hambat awal $(80,83 \%)$. Tingginya daya hambat pada formulasi F2 didukung pula oleh kecepatan pertumbuhan yang tinggi dibandingkan pada formulasi lainnya (Gambar 1B).

Tabel 1. Rerata daya hambat koloni jamur T. pseudokoningii terhadap pertumbuhan jamur G. boninense dari formulasi biofungisida tepung di medium PDA setelah penyimpanan $(\%)$

Komposisi Bahan Organik di dalam Formulasi

Daya Hambat T. pseudokoningii terhadap pertumbuhan jamur G. boninense (\%)

\begin{tabular}{lcc}
$\left(\mathrm{F}_{1}\right)$ Ampas Tebu & $75,73 \mathrm{a}$ & $74,24 \mathrm{~b}$ \\
$\left(\mathrm{~F}_{2}\right)$ Sekam Padi & $78,54 \mathrm{a}$ & $78,23 \mathrm{a}$ \\
$\left(\mathrm{F}_{4}\right)$ Dregs & $43,02 \mathrm{c}$ & $46,89 \mathrm{~d}$ \\
$\left(\mathrm{~F}_{12}\right)$ Ampas Tebu + Sekam Padi + Dregs & $57,15 \mathrm{~b}$ & $58,74 \mathrm{c}$ \\
\hline
\end{tabular}

Keterangan: Angka-angka yang diikuti oleh huruf kecil yang tidak sama adalah berbeda nyata menurut uji DNMRT pada taraf 5\%.

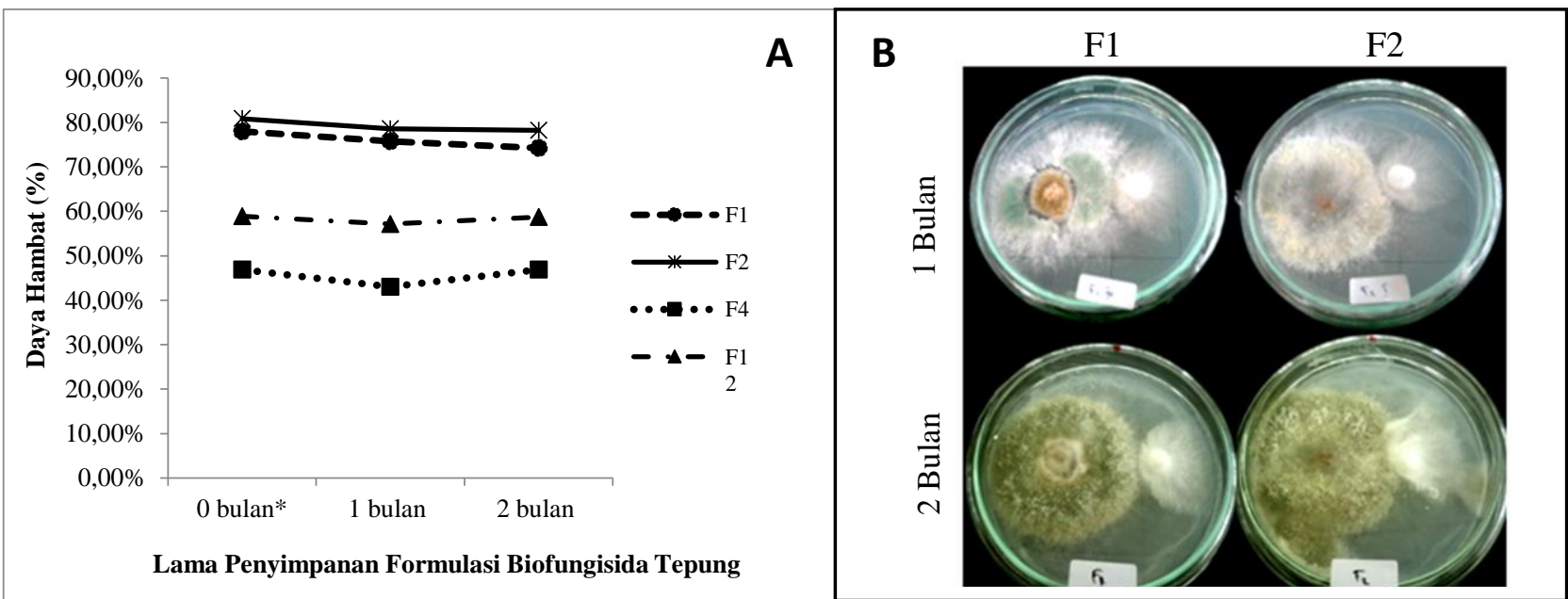

Gambar 2. Tren daya hambat jamur Trichoderma pseudokoningii (A) dan uji penghambatan dual culture (B) terhadap jamur ganoderma boninense pada formulasi biofungisida tepung setelah penyimpanan (*Elfina et al., 2016) 
Tersedianya nutrisi di dalam komposisi formulasi biofungisida tersebut, maka jamur $T$. pseudokoningii dapat berkembang dengan baik, karena jamur $T$. pseudokoningii memiliki kemampuan yang lebih cepat dalam memenuhi ruang dan memanfaatkan nutrisi yang ada dibandingkan jamur $G$. boninense. Purwantisari dan Hastuti (2009) menyatakan bahwa jamur Trichoderma sp. bersifat hiperparasit terhadap beberapa jamur patogen tanaman dan memiliki pertumbuhan yang cepat. Menurut Gholib dan Kusumaningtyas (2006), jamur T. viride mampu tumbuh secara agresif dengan menutupi koloni jamur lain dan dapat menghambat pertumbuhan jamur Fusarium moniliforme.

Bahan penyusun formulasi biofungisida juga mempengaruhi kemampuan mikroorganisme dalam menghasilkan senyawa-senyawa antibiosis. Al-Zahrani (2007) menyatakan bahwa komposisi medium mempengaruhi enyawa antibiosis. Penelitian Saputra et al. (2015) juga menunjukkan bahwa beberapa isolat Bacillus sp. menghasilkan zona penghambatan berbeda terhadap Ralstonia solanacearum karena perbedaan kandungan nutrisi pada media yang digunakan.

\section{KESIMPULAN}

Hasil penelitian menunjukkan formulasi biofungisida tepung F2 (sekam padi) mampu menjaga viabilitas jamur $T$. pseudokoningii yang ditunjukkan dengan banyaknya jumlah konidia dan tingginya kecepatan pertumbuhan dibandingkan formulasi lasinnya. Jamur T. pseudokoningii pada formulasi F2 juga menunjukkan daya hambat tertinggi dibandingkan dengan formulasi lainnya setelah penyimpanan 1 dan 2 bulan.

\section{DAFTAR PUSTAKA}

Al-Zahrani, S.H.M. 2007. Studies on the antimicrobial activity of Streptomyces sp. isolate from Jazan. JKAU Sci 19: 127-138.

Elfina, Y., M. Ali, dan R. Saputra. 2016. Penggunaan bahan organik dan kombinasinya dalam formulasi biofungisida berbahan aktif jamur Trichoderma pseudokoningii Rifai. untuk menghambat jamur Ganoderma boninense Pat. secara in vitro. Jurnal Natur Indonesia 16: 7990. DOI: 10.31258/jnat.16.2.79-90

Gholib, D. dan E. Kusumaningtyas. 2006. Penghambatan Pertumbuhan Fusarium moniliforme oleh Trichoderma viride. Prosiding pada Seminar Nasional Teknologi Peternakan dan Veteriner. Hlm. 1018-1025.
Hidayati, A.S.D.S.N., S. Kurniawan, N.W. Restu, dan B. Ismuyanto. 2016. Potensi ampas tebu sebagai alternatif bahan baku pembuatan karbon aktif. Natural B 3: 311-317.

Kharisma, N. 2011. Uji Konsentrasi Dregs terhadap Trichoderma pseudokoningii T-ks dan Pengaruhnya pada Ganoderma boninense Pat. Secara In vitro. Skripsi. Fakultas Pertanian, Universitas Riau. Pekanbaru.

Muljowati, J.S. dan Purnomowati. 2010. Pengaruh kombinasi jenis bahan pembawa dan lama masa simpan yang berbeda terhadap produksi pelet biofungisida Trichoderma harzianum. Majalah Ilmiah Biologi Biosfera 27: 22-29. DOI: $10.20884 / 1 . m i b .2010 .27 .1 .188$

Naufala, W.A. dan S. Pandebesie. 2015. Hidrolisis enceng gondok dan sekam padi untuk menghasilkan gula reduksi sebagai tahap awal produksi bioetanol. Jurnal Teknik ITS 4: B109B114. DOI: 10.12962/j23373539.v4i2.11308

Ratanaphadit, K., K. Kaewjan, and S. Palakas. 2010. Potential of glycoamylase and cellulase production using mixed culture of Aspergillusniger TISTR 3254 and Trichodermareesei TISTR 3081. KKU Research Journal 15: 833-842.

Saputra, R., T. Arwiyanto, dan A. Wibowo. 2015. Antagonistic activity and identification of some isolates of Bacillus spp. against Bacterial Wilt Diseases (Ralstonia solanacearum) in some varieties of tomato. Prosiding of Indonesia Biodiversity 1: 1116-1122. DOI: 10.13057/psnmbi/m010525

Sastrahidayat, I.R. 1986. Ilmu Penyakit Tumbuhan. Usaha Nasional. Surabaya. $365 \mathrm{hlm}$.

Semangun, H. 2006. Pengantar Ilmu Penyakit Tumbuhan. Gadjah Mada University Press. Yogyakarta. $754 \mathrm{hlm}$.

Soepena, H. 1993. Pemberantasan jamur akar putih dengan Trichoderma. Warta Perkebunan 12: 1722.

Suswanto, I. 2014. Kajian formulasi mutan Trichoderma sebagai kandidat agens pengendali hayati hawar beludru Septobasidium pada lada. Jurnal Perkebunan dan Lahan Tropika 4: 22-29. DOI: 10.26418/plt.v4i2.9373.

Untung, K. 2006. Pengantar Pengelolaan Hama Terpadu. Edisi Kedua, Gajah Mada University Press. Yogyakarta. 348 hlm.

Weller, D.M. and R.J. Cook. 1983. Suppression of takeall of wheat by seed treatments with fluorescent pseudomonads. Phytopathology 73: 463-469. 